\title{
Are Biased Media Bad for Democracy?
}

\author{
Short title: Are Biased Media Bad for Democracy?
}

Keywords: omission bias, presentation bias, accountability, counterfactual

\section{Stephane Wolton*}

Postal address: Department of Government, London School of Economics and Political Science, Houghton Street, London WC2A 2AE, United Kingdom

Email: s.wolton@lse.ac.uk

*I thank Chris Berry, Scott Ashworth, Ethan Bueno de Mesquita, Ernesto Dal Bó, Mariaelisa Epifanio, Marco Giani, Helios Herrera, Selina Hofstetter, Rafa Hortala-Vallve, Navin Kartik, Pablo Montagnes, Erik Snowberg, Richard Van Weelden, and many seminar and conference participants for their helpful comments. Pablo Montagnes and Scott Tyson coined the term 'Theoretical Implications of Empirical Models' used in the conclusion of this paper. All remaining errors are the author's responsibility. 


\title{
Are Biased Media Bad for Democracy?
}

\begin{abstract}
This paper assesses the normative and positive claims regarding the consequences of biased media using a political agency framework that includes a strategic voter, polarized politicians, and news providers. My model predicts that voters are always better informed with unbiased than biased outlets even when the latter have opposite ideological preferences. However, biased media may improve voter welfare. Contrary to several scholars' fears, partisan news providers are not always bad for democracy. My theoretical findings also have important implications for empirical analyses of the electoral consequences of changes in the media environment. The impact of left-wing and right-wing biased outlets depends on the partisan identity of office-holders. Empirical findings may, thus, not be comparable across studies or even within studies over time. Existing empirical studies are unlikely to measure the consequences of biased media as researchers never observe and can rarely approximate the adequate counterfactual: elections with unbiased news outlets.
\end{abstract}

Replication Materials: Not relevant for this article

Word count: approx 9,980 words 
There is a broad consensus that news outlets are politically biased. Politicians commonly assert it. The broader public in the U.S (Newseum Institute, 2017) and elsewhere (Reuters Institute, 2015) believes it. And multiple academic studies have confirmed it (Puglisi and Snyder, 2015a). But are biased news providers harmful for democracy?

Some argue so (e.g., Entman, 1989; McChesney, 2004; Ladd, 2012). Broadly speaking, these scholars argue that through omission or presentation bias, partisan outlets - newspapers, television channels, or radio stations - reduce the information available to the electorate. As information is key to holding politicians accountable, democracy faces "a political crisis of the highest magnitude" (McChesney, 2004, 18). In a time of high political polarization when politicians are often misaligned with the electorate, this problem appears especially acute. As Prior puts it (2013, 123), "The median voter has never been so bored."

This paper assesses the normative claims regarding the consequences of biased media. To do so, I use a political agency framework in which a representative voter faces the dual problem of controlling and selecting polarized politicians. I analyse equilibrium behaviors under four different media environments. In the first one, the voter is informed by a news outlet who shares her policy preference, an environment I refer to as 'unbiased.' In the second, the voter receives news reports from two biased media outlets, ideologically located to the right and the left of the voter. Since the voter is exposed to diverse viewpoints, I describe this environment as 'balanced.' The remaining two cases correspond to 'right-wing biased' and 'left-wing biased' media environments in which the voter's information comes from a single right-wing or left-wing news provider, respectively.

I compare the equilibrium behaviors of all actors - outlet(s), the voter, and politicians - across media environments. In line with the literature, I show that the voter is always less informed with biased news providers (whether the environment is balanced or not) than with an unbiased outlet. Keeping the office-holders' actions constant, the voter's welfare would be maximized in an unbiased media environment. However, when electoral incentives are sufficiently strong, I show that politicians' behavior changes with the media environment. Taking into account these equilibrium effects, I find that the voter is better off with two (or even one) biased news providers than with an unbiased outlet. Therefore, the often expressed opinion that media bias is bad for democracy needs to be qualified.

I study a two-period game. There is a single election at the end of the first period when the voter decides whether to reelect the incumbent or to replace him with a randomly drawn challenger. Each 
period, the office-holder makes a policy choice. The impact of the implemented policy depends on an underlying state of the world that is directly observed by the office-holder, but not by the voter. The voter would like the policy chosen to always match the state; the incumbent's ideal policy is to the right of the voter, and the challenger's to the left. Further, politicians can be either extremist or moderate. Extremists are non-strategic. An incumbent, if extremist, always chooses the most right-wing policy; a challenger, if extremist, always implements the most left-wing policy. Moderates respond to electoral incentives. An incumbent, even if moderate, has policy preference to the right of the voter's; a challenger, even if moderate, to the left. Whether a politician is moderate or extremist is his private information, or type.

In the second period, after the election, the office-holder no longer faces any electoral constraint. Hence, he always chooses his preferred policy. Since an extremist's policy preferences are further away from the voter's, the voter elects the politician she believes is more likely to be moderate. Before making her electoral decision, the voter observes the incumbent's policy choice, which may reveal information about his type. She also receives a news report from one or two outlets depending on the media environment. This report contains an editorial, or opinion piece, which takes the form of falsifiable information about the incumbent's type (moderate or extremist). This report may also include a news story, which takes the form of verifiable information about the state of the world. The model thus encompasses the possibility for presentation bias (outlets can lie about type in their editorial) and omission bias (outlets can omit information by hiding news stories).

Turning to the unbiased media environment, the news provider, like the voter, seeks to maximize the likelihood that a moderate incumbent is reelected and an extreme incumbent replaced. The outlet thus truthfully discloses all of its information. The voter is perfectly informed about the incumbent's type and effectively screens politicians. As a result, an unbiased news provider is optimal for selection. However, this comes at a cost. The incumbent's reelection prospects depend on the media report, which reveals his type, not on his policy choice. A moderate incumbent then implements his preferred policy, which differs from the voter's. Hence, an unbiased news provider induces a loss of control.

In contrast to an unbiased outlet, a right-wing news provider would prefer the incumbent to be reelected; a left-wing outlet the incumbent to be replaced; neither shares the voter's electoral objective. This has dramatic consequences for editorials. I show that, even in a balanced media 
environment, editorials suffer from presentation biases and can never be trusted by the voter. The voter, however, is not completely uninformed with biased news providers. The left-wing outlet always publishes bad news for the incumbent (i.e., stories that hurt his electoral chances), while the right-wing outlet shares good news (i.e., stories that improve his prospects).

Reduced information entails some loss in term of selection. Lacking information about the incumbent's type, the voter becomes more likely to incorrectly reelect an extremist or replace a moderate. But a moderate politician now has some incentive to choose a first-period policy that signals his type and improves his electoral prospects. To distinguish himself from an extremist, a moderate incumbent implements a policy closer to the state of the world and, thus, to the voter's ideal point. As a result, with biased media outlets, the voter gains some control over the incumbent.

The analysis reveals that an unbiased news provider is good for selection, but bad for control, whereas the reverse holds true for biased outlets. Selecting moderates is not so valuable with misaligned politicians. Absent electoral incentives, moderates generally do not choose the voter's preferred policy. In turn, controlling politicians implies that a moderate incumbent's first-period choice is aligned with the voter's ideal policy. Hence, better control dominates worse selection, and voter welfare is higher with biased outlets.

My results also have some implication for positive analysis of biased media. First, empirical studies are unlikely to measure the electoral consequences of biased media. To recover this effect, researchers need to compare electoral results in biased and unbiased media environments. But a researcher's baseline is almost always a balanced media environment. While an unbiased outlet truthfully reports all information, editorials from biased news providers always suffer from presentation bias. Because the electorate is more informed with unbiased media, a balanced environment is a poor approximation for an unbiased one, even absent any change in office-holders' behavior.

Further, as noted above, a partisan outlet hides bad news for office-holders who shares the outlet's ideology and hides good news for politicians whose politics do not match those of the outlet. Hence, the electoral impact of a change in the media environment is a function of both the partisan identity of the office-holder (right-wing or left-wing incumbent) and the direction of the change (from balanced to a right- or a left-wing biased media environment). As a result, researchers should be careful interpreting varying estimates over time, especially if the political context is not constant (as in Martin and Yurukoglu, 2017). To facilitate comparability of findings 
across studies or over time within a study, this paper recommends that researchers provide detailed descriptions of the media and political environments they study.

Before connecting my work with the formal literature, a word of caution is in order. This work does not argue that biased media are unambiguously good or that empirical studies of media bias are inherently flawed (I discuss the interpretation of findings, not the internal validity of research designs). The claims of this paper are more modest, but nonetheless necessary. The results above stress that changing the media environment modifies the information available to voters, while also altering politicians' behavior. Looking only at the impact of biased outlets on voter information or on electoral outcomes is insufficient for passing judgement on biased media. Any normative or empirical evaluation of the consequences of biased media must also take into account politicians' actions.

\section{Related formal literature}

The formal literature on biased media is divided into two broad themes: (i) an economic literature that tries to uncover its origin (reviewed in Gentzkow et al., 2015a) and (ii) a political economy literature that assesses the impact of media bias (reviewed in Strömberg, 2015). This paper belongs to this last category.

In many works on the political consequences of biased media, voters seek to pick the best alternatives among a fixed choice set, a pure adverse selection problem. Biased media outlets then tend to reduce voters' welfare since they provide less information (e.g., Bernhardt et al., 2008; Duggan and Martinelli, 2010; Shapiro, 2016). Scholars, however, have identified several factors that mitigate the negative impact of biased media. Mullainathan and Shleifer (2005) assume that readers have confirmation bias and thus enjoy some utility from reading biased news. Chen (2007), Sobbrio (2011), and Warren (2012), in various frameworks, assume that collecting news is costly. Since biased news providers have more to gain from convincing their readership, they expend more effort in news collection and may end up providing more information than unbiased outlets. Competition can also reduce the detrimental effect of media bias as readers then get to learn all possible non-falsifiable news stories (Anderson and McLaren, 2012; Piolatto and Schuetts, 2015).

A few papers consider the impact of media bias in variants of the Downsian framework. There, the electorate's main problem is to control politicians. Overall, whether media outlets inform voters 
about candidates' platform (Chan and Suen, 2009; Miura, 2018) or their character (Chakraborty and Ghosh, 2016), biased media tends to generate polarized platforms as candidates distort their policy promises to appeal to biased news providers and gain positive coverage. This polarization, in turn, reduces the electorate's welfare.

As argued by Fearon (1999) and many after him (e.g., Canes-Wrone et al., 2001; Maskin and Tirole, 2004; Ashworth and Bueno de Mesquita, 2014), the electorate rarely faces a pure control or a pure selection problem. Voters use politicians' past actions to infer their future behavior. In such political agency framework, scholars have long been interested in the effect of transparency (e.g., Prat, 2005; Fox, 2007; Fox and Van Weelden, 2012). In these important works, voters receive exogenous signals. Instead, I assume that a representative voter is informed by strategic media outlets.

As such, my work is in close conversation with Ashworth and Shotts (2010), Gratton (2015), and Hafer et al. (2016), all of whom study political agency models with a strategic media outlet (Adachi and Hizen 2014 assume that biased outlets exogenously garble information). The present manuscript differs from these papers in three important dimensions. First, news providers do not share the same objective. Ashworth and Shotts consider a truth-motivated news provider, Gratton and Hafer et al. assume outlets maximize profit, and none studies biased outlets. Second, my framework is unique in incorporating both presentation and omission biases. Ashworth and Shotts focus on presentation bias, Gratton on omission bias, Hafer et al. on costly news production. Finally, I derive novel empirical implications that help interpret findings regarding the electoral consequences of changes in the media environment.

\section{The model}

I study a two-period $(t \in\{1,2\})$ game with strategic news outlets, politicians, and a (representative) voter. Each period, the office-holder chooses a policy $x_{t} \in\{-1,0,1\}$, with $-1,0$, and 1 , respectively, the left-wing, centrist, and right-wing policy. Without loss of generality, the firstperiod incumbent $(R)$ leans right, and his challenger $(L)$ leans left. At the end of period 1, the voter decides to reelect politician $R$ or elect $L$ after observing: (i) the first-period policy choice $\left(x_{1}\right)$ and (ii) one or two news outlets' reports, depending on the media environment. The rest of 
the section describes in greater detail the various aspects of the model starting with players' policy preferences.

\section{Policy preferences}

Policy preferences build on Morelli and Van Weelden (2013). The representative voter's policy preference depends on an underlying state of the world $\omega_{t} \in\{l, c, r\}, t \in\{1,2\}$. It is common knowledge that the state is drawn i.i.d. each period according to the following distribution: $\operatorname{Pr}\left(\omega_{t}=l\right)=\operatorname{Pr}\left(\omega_{t}=r\right)=\pi \in(0,1 / 3], t \in\{1,2\}$. (The assumption of symmetry is meant to simplify the exposition.) The voter prefers the centrist policy 0 in state $\omega=c$, the left-wing policy -1 in state $l$, and the right-wing policy 1 in state $r$.

Politicians' preferences are a function of their type and the state of the world. Politician $J \in\{R, L\}$ is either extremist $\tau=e$ or moderate $\tau=m$. It is common knowledge that a politician is moderate with probability $\kappa \in(0,1): \operatorname{Pr}(\tau=m)=\kappa$. An extremist politician is non-strategic. He always implements policy 1 if right-wing and policy -1 if left-wing. A moderate politician responds to electoral incentives. Further, like the voter, a type- $m$ politician prefers the left-wing policy in state $\omega=l$ and the right-wing policy in state $\omega=r$. Politicians' and the voter's policy preferences diverge in the centrist state: a moderate $R$ prefers the right-wing policy $x=1$, a moderate $L$ prefers the left-wing policy $x=-1$.

News outlets also have policy preferences. I say that an outlet is unbiased if it shares the voter's policy preference. In turn, an outlet exhibits a right-wing bias if it shares the preferences of a moderate politician $R$ and a left-wing bias if it has similar policy preferences to a moderate challenger $L$. All conclusions remain unchanged when biased outlets always prefer extreme policies.

I use the label $N^{U}$ for the unbiased outlet, $N^{R}$ for the right-wing outlet, and $N^{L}$ for the left-wing outlet.

Table 1 summarizes the ideal policies of all strategic players as a function of the state $\omega$, which I denote $x^{K}(\omega), K \in\left\{V, R, L, N^{U}, N^{L}, N^{R}\right\}$. Observe that all players agree in states $l$ and $r$. Thus, these states are assumed to be relatively rare $(\pi \leq 1 / 3)$. 


\begin{tabular}{c|c|c|c} 
Players/States & $l$ & $c$ & $r$ \\
\hline Voter $V$ & -1 & 0 & 1 \\
\hline Moderate $R$ & -1 & 1 & 1 \\
\hline Moderate $L$ & -1 & -1 & 1 \\
\hline Unbiased outlet $N^{U}$ & -1 & 0 & 1 \\
\hline Right-wing outlet $N^{R}$ & -1 & 1 & 1 \\
\hline Left-wing outlet $N^{L}$ & -1 & -1 & 1
\end{tabular}

Table 1: Players' preferred policies as a function of the state $\omega\left(x^{K}(\omega)\right)$

\section{Payoffs}

A moderate politician and news outlets' per-period payoff simply depends on the distance between their ideal policy in state $\omega_{t} \in\{l, c, r\}$ and the policy implemented $x_{t}$.

$$
U^{K}\left(x_{t}\right)=-\left|x_{t}-x^{K}\left(\omega_{t}\right)\right|, K \in\left\{R, L, N^{U}, N^{L}, N^{R}\right\}
$$

The voter's payoff depends on the distance between her ideal policy $x^{V}(\omega)$ and the policy choice as well as a valence shock $\xi$, which captures the voter's evaluation of other aspect of politician $R$ 's performance (e.g., charisma) or various aspects of the political environment in a reduced form (e.g., partisanship). $V$ observes $\xi$ after $x_{1}$ is implemented but before making her electoral decision. I assume that $\xi$ is distributed according to the cumulative distribution function (CDF) $F(\xi)$, continuous and strictly increasing over $[-2(1-\kappa) \pi, 2 \kappa \pi]$. The voter's payoff assumes the following form:

$$
U^{V}\left(x_{t}\right)= \begin{cases}-\left|x_{t}-x^{V}(\omega)\right|+\xi & \text { if } R \text { in office } \\ -\left|x_{t}-x^{V}(\omega)\right| & \text { otherwise }\end{cases}
$$

Players do not discount the future.

\section{Information}

The voter never directly learns the state of the world $\omega_{t} \in\{l, c, r\}$ or the office holder's type $\tau \in\{e, m\}$. She always observes the incumbent $R$ 's first-period policy choice $x_{1} \in\{-1,0,1\}$ and one or two news reports before making her electoral decision. A politician always observes his type 
and the state of the world before making his policy choice, as do outlets before publicizing their report.

\section{Outlets' reports}

Outlet $N$ 's report is denoted $n^{N}$. I focus exclusively on editorials and news stories. An editorial, or opinion piece, $o^{N} \in\{m, e\}$ contains falsifiable and non-verifiable (soft) information about politician $R$ 's type. A news story $s^{N} \in\left\{\emptyset, d^{N}\right\}$ possibly contains non-falsifiable and verifiable (hard) information about the state of the world. Outlets uncover a news story probabilistically. This is captured by the variable $d^{N}$ which takes value $d^{N}=\omega_{1}$ with probability $\rho \in(0,1)$ if a news story is uncovered and $d^{N}=\emptyset$ otherwise. The parameter $\rho$ can be interpreted as media quality. To guarantee that the media environment only changes outlets' strategic reporting (and to simplify the exposition), I assume that outlets simultaneously uncover news stories: $d^{N^{U}}=d^{N^{L}}=d^{N^{R}}=d \in\left\{\emptyset, \omega_{1}\right\}$.

\section{Media environment}

The media environment is said to be 'unbiased' if outlet $N^{U}$ makes a report. When both $N^{L}$ and $N^{R}$ publish a report, I follow Puglisi and Snyder (2015b) and describe the environment as 'balanced' (e.g., most U.S. states). The media environment exhibits a 'right-wing bias' if the proincumbent outlet $N^{R}$ is the unique news provider (e.g., Italy after Berlusconi's election in 1994, see Durante and Knight, 2012) and a 'left-wing bias' if only $N^{L}$ makes a report. ${ }^{1}$

\section{Timing}

Period 1:

0. Nature draws the first-period state of the world $\left(\omega_{1} \in\{l, c, r\}\right)$ and politicians' types $\left(\left(\tau^{R}, \tau^{L}\right) \in\right.$ $\left.\{m, e\}^{2}\right)$

1. Politician $R$ observes his type $\tau^{R}$, the state of the world $\omega_{1}$ and chooses policy $x_{1} \in\{-1,0,1\}$;

2. News outlet $N$ observes the first-period policy $\left(x_{1}\right), R$ 's type $\left(\tau^{R}\right)$, and news story $\left(d^{N} \in\right.$ $\left.\left\{\emptyset, \omega_{1}\right\}\right)$. It then publishes a news report $n^{N} \in\{m, e\} \times\left\{\emptyset, d^{N}\right\}$;

3. Voter observes the first-period policy, the outlet's or outlets' reports $n^{N}$, and the valence shock $\xi$. She then decides whether to reelect $R$;

${ }^{1} \mathrm{~A}$ biased media environment can also be interpreted (ignoring the important problem of self-selection) as an echo chamber. 
Period 2:

0. Nature draws the second-period state of the world $\omega_{2} \in\{l, c, r\}$;

1. The office-holder ( $R$ or $L$ ) observes his type, the state of the world, and chooses policy $x_{2} \in\{-1,0,1\}$

2. The game ends and payoffs are realized

\section{Equilibrium concept}

The equilibrium concept is Perfect Bayesian Equilibrium (PBE). A common problem in political agency models is the multiplicity of equilibria which makes comparison across media environments difficult. To solve this issue, I impose several refinements that, combined, guarantee uniqueness. First, I restrict politicians' strategies (but not outlets') to pure strategies. Second, editorials must be directly interpretable when truthful (e.g., contain $m$ if $R$ is moderate) and type-invariant when uninformative (e.g., contain $m$ for all types $\tau^{R} \in\{m, e\}$ ). Third, the voter believes that $R$ is moderate if he chooses the centrist policy 0 or the left-wing policy -1 (recall an extremist $R$ always chooses 1). Fourth, I select the most informative PBE. Finally, I focus on the PBE which maximizes the voter's ex-ante expected policy payoff (henceforth, 'policy welfare'). In Supplemental Appendix A (pages 3-5), I provide a formal definition of PBE in this framework (see Definition A.1, page 3) and discuss in greater detail the equilibrium refinements. In what follows, I use the term 'PBE' when I characterize strategies that satisfy Definition A.1. The term 'equilibrium' refers to PBE satisfying the five refinements.

\section{Remarks on the set-up}

Before proceeding to the analysis, a few remarks on the set-up are in order. I focus on a political environment which exhibits significant elite polarization, like the United States in recent years (Bonica et al., 2013). Even moderate politicians do not share the voter's policy preferences. This guarantees that the voter faces a double problem of controlling and selecting politicians. If moderate politicians resemble the voter, hers is a problem of selection, and unbiased outlets always perform better. In turn, if moderate and extremist politicians have similar preferences (with moderates responsive to electoral incentives), the selection problem is mute - the voter is always indifferent between $R$ and $L$ at the time of the election-and the media environment has no effect. 
My framework incorporates two distinct reporting biases: 'presentation bias' (or 'news distortion') with editorials and 'omission bias' (or 'news filtering') with news story. A media outlet $N$ 's report suffers from severe presentation bias if its editorial provides no information about the incumbent's type (i.e., outlet $N$ babbles). In turn, $N$ 's report is free of presentation bias if and only if its editorial always reveals the incumbent's type. Let a media outlet $N$ 's editorial strategy be $o^{N}:\{m, e\} \rightarrow\{m, e\}$ (ignoring $x_{1}$ for simplicity), a formal definition is:

Definition 1. A media outlet $N$ 's report suffers from severe presentation bias when for all $\tau^{R} \in$ $\{m, e\}, o^{N}\left(\tau^{R}\right)=z \in\{m, e\}$.

A media outlet $N$ 's report is free from presentation bias if and only if for all $\tau^{R} \in\{m, e\}, o^{N}\left(\tau^{R}\right)=$ $\tau^{R}$.

In turn, outlet $N$ 's report suffers from omission bias if and only if $N$ hides a story it uncovered. Let a media outlet $N^{\prime}$ 's news story strategy be $s^{N}: d^{N} \rightarrow\left\{\emptyset, d^{N}\right\}$ (again ignoring $x_{1}$ ), a formal definition is:

Definition 2. A media outlet $N$ 's report suffers from omission bias whenever $s^{N}(\omega)=\emptyset$. A media outlet $N$ 's report is free from omission bias if and only if $s^{N}(\omega)=\omega$.

Finally, let me acknowledge that the equilibrium restrictions play a significant role in establishing the normative results below. In particular, the focus on the most informative PBE, while common, is not innocuous. There are several justifications for this choice. This refinement guarantees that any reporting bias is the result of strategic interactions rather than equilibrium selection. Further, the most informative PBE is the only renegotiation-proof PBE between an unbiased outlet and the voter. In fact, an unbiased news provider would even be willing to pay a cost (e.g., printing a special edition) to credibly signal its report is free of presentation bias.

\section{Equilibrium analysis}

In this section, I first discuss the second-period office-holder's behavior and the voter's electoral decision. I then describe outlet $N^{U}$ and incumbent $R$ 's equilibrium first-period strategies Finally, I consider both balanced and biased media environments. 


\section{Voter's electoral decision}

In period 2, absent any electoral pressure, a moderate office-holder always implements his preferred policy. Using Table 1, a moderate $R$ chooses $x_{2}=1$ in the right-wing and centrist states and $x_{2}=-1$ in state $\omega_{2}=l$; a moderate $L$ chooses $x_{2}=-1$ in the left-wing and centrist states and $x_{2}=1$ in state $\omega_{2}=r$. By symmetry, the voter's expected payoff when a moderate is in office is $-(1-2 \pi)$. An extremist $R$ always implements $x_{2}=1$ and an extremist $L x_{2}=-1$ so the voter's expected policy payoff when the office-holder is extremist is -1 .

After observing the first-period policy choice $x_{1}$ and the outlet's or outlets' news report $n, V$ forms a posterior that $R$ is moderate, which I denote $\mu^{V}\left(x_{1}, n\right)$. The voter's expected policy payoff from reelecting $R$ is $\mu^{V}\left(x_{1}, n\right)(-(1-2 \pi))+\left(1-\mu^{V}\left(x_{1}, n\right)\right)(-1)$. For the challenger, the voter can only rely on her prior. Her expected payoff from electing $L$ is then $\kappa(-(1-2 \pi))+(1-\kappa)(-1)$. The voter thus reelects the incumbent $R$ if and only if (after slight rearranging and with indifference a zero probability event):

$$
\mu^{V}\left(x_{1}, n\right) 2 \pi+\xi \geq \kappa 2 \pi
$$

Since the voter observes $\xi$ after the report(s) or policy choice, outlet(s) and politician $R$ treat $\xi$ as random. From their perspective, $R$ is reelected with probability

$$
P\left(\text { reelection } \mid \mu^{V}\right) \equiv 1-F\left(\left(\kappa-\mu^{V}\left(x_{1}, n\right)\right) 2 \pi\right),
$$

with $F\left(\left(\kappa-\mu^{V}\left(x_{1}, n\right)\right) 2 \pi\right) \in[0,1]$ for all $\mu^{V}(\cdot) \in[0,1]$ under the assumptions.

\section{Unbiased media environment}

First, consider outlet $N^{U}$ 's reporting strategy. At the time of its report, the outlet can only influence the voter's electoral decision. Since it shares the voter's preferences, the outlet seeks to maximize the probability that the second-period office-holder is moderate. $N^{U}$ thus reveals the incumbent's type in its editorial. Further, it also discloses any news story it uncovers. Using Definitions 1 and 2, I obtain:

Lemma 1. In equilibrium, the unbiased news outlet $N^{U}$ 's report is free of presentation and omission biases. 
Proof. All proofs for the 'Equilibrium Analysis' are collected in the Supplemental Appendix B (pages 6-29).

Since $N^{U}$ 's editorial reveals $R$ 's type, $R$ 's first-period action has no effect on his electoral prospect. Thus, a moderate $R$ always chooses his preferred policy in the first period, $x^{R}(\cdot)$.

Proposition 1. In an unbiased media environment, in equilibrium, in all states $\omega_{1} \in\{l, c, r\}, a$ moderate $R$ 's first-period policy choice is his preferred policy $x^{R}\left(\omega_{1}\right)$.

\section{Balanced media environment}

In a balanced media environment, the voter receives reports from both the right-wing outlet $N^{R}$ and the left-wing outlet $N^{L}$. While the policy preferences of outlets $N^{R}$ and $N^{L}$ are, on average, the same as the unbiased outlet $N^{U}$ 's, there is a fundamental difference. The right-wing biased outlet $N^{R}$ prefers a moderate $R$ to an extreme $R$, but also an extreme $R$ to any left-wing politician. The left-leaning outlet $N^{L}$ prefers a random politician $L$ to a moderate $R$, let alone an extreme incumbent. No biased outlet shares the voter's ranking of politicians' types. As a result, biased outlets' reporting differs from an unbiased news provider's whenever their reports can influence the voter's electoral decision.

Lemma 2. Suppose the media environment is balanced. Consider a first-period equilibrium policy choice that does not reveal politician $R$ 's type. Then,

(i) $N^{L}$ and $N^{R}$ 's reports suffer from severe presentation bias;

(ii) One outlet's report is free of omission bias.

Any difference in reporting between a balanced and unbiased media environment can be attributed to editorials. When it comes to a news story, the media environment as a whole is always free of omission bias in all states. The left-wing outlet $N^{L}$ always has an incentive to disclose information that hurts the incumbent $R$, and vice versa for the right-wing outlet $N^{R}$ (see Milgrom and Roberts, 1986).

The same logic does not apply to editorials. To build intuition for this result, suppose that there exists a PBE in which both news outlets' reports are free of presentation bias. Both outlets' editorials should then have the same content, and any difference necessarily implies that one outlet has lied. The voter, however, does not know which provider did not truthfully report the 
incumbent's type. Suppose she believes after observing $o^{N^{L}} \neq o^{N^{R}}$ that outlet $N^{R}$ deviated. To deter the right-wing outlet from lying, the voter must punish $N^{R}$ by believing that $R$ is almost certainly an extremist, reducing $R$ 's electoral chances. But this punishment strategy generates an incentive for the left-wing outlet to engage in presentation bias. (Lemma B.4 in Appendix B, page 8 shows that the logic extends to all possible editorial strategies.) Because elections are a coarse instrument, in two-candidate elections, one news outlet's punishment is always the other's reward, and the voter cannot encourage truth telling. ${ }^{2}$

With presentation bias, the incumbent's first-period policy choice influences the voter's electoral decision. A moderate politician $R$ now has some electoral incentive to choose the centrist policy to signal his type. The strength of these electoral incentives depends on two components. First, it is a function of the electoral benefit from choosing policy $x_{1}=0$. This benefit is bounded by $(1-F(-(1-\kappa) 2 \pi))-(1-F(-(0-\kappa) 2 \pi))$ since a moderate $R$ can at most change the voter's posterior from 0 to 1 (see Equation 2). Second, the strength of electoral incentives depends on the expected payoff gain from staying in office rather than being replaced by his challenger $L$, which I denote $\Delta^{R}\left(\Delta^{R}=\kappa \times(1-2 \pi) \times 2+(1-\kappa) \times((1-2 \pi) \times 2+\pi \times 2)\right)$.

When deciding whether to implement $x_{1}=0$ in state $c$ or $r$, a moderate $R$ compares the associated future gain (electoral benefit and second-period payoff gain) with the associated firstperiod payoff loss of not choosing his preferred policy, which equals -1 . When the maximum gain $\left((F((1-\kappa) 2 \pi)-F((0-\kappa) 2 \pi)) \Delta^{R}\right.$ by the reasoning above) is lower than the cost, electoral incentives are too weak to induce a change in a moderate type's first-period behavior. A moderate $R$ then behaves as if there were no election.

When electoral incentives are relatively strong, two PBE, which I label 'fully revealing PBE' and 'full control PBE,' are worth studying. In a fully revealing PBE, a moderate $R$ chooses the centrist policy 0 in both the centrist and right-wing states. (In the left-wing state, a moderate $R$ always chooses $x_{1}=-1$ which maximizes his first-period payoff and reelection chances.) Upon observing $x_{1}=0$, the voter learns that the incumbent is moderate and reelects him with probability $1-F(-(1-\kappa) 2 \pi)$. If a moderate were to deviate and choose $x_{1}=1$, he would be believed to be

\footnotetext{
${ }^{2}$ The voter's inability to induce truth telling from competing outlets is due to her finite set of options; here, two candidates (for a theoretical discussion, see Battaglini, 2002). It survives changes in the timing (one outlet reporting before the other), adding a third candidate (as long as the voter's second preferred choice is not $N^{L}$ 's least preferred option), or even introducing more outlets after excluding weakly dominated strategies (any right-leaning outlet that learns the incumbent is extremist has nothing to lose from lying, and vice versa for a left-leaning outlet).
} 
an extreme type and reelected with probability $1-F(\kappa 2 \pi)$. Thus, a fully revealing PBE exists if and only if $(F(\kappa 2 \pi)-F(-(1-\kappa) 2 \pi)) \Delta^{R} \geq 1$.

In a full control PBE, a moderate $R$ chooses the voter's preferred policy in all states. In addition to the condition above, a moderate $R$ also faces an electoral risk by choosing the rightwing policy in state $r$. In this instance, the voter believes with high probability that the incumbent is an extremist who always implements $x_{1}=1$. A moderate's reelection chances are then at most $1-F((\kappa-\kappa) 2 \pi)=1-F(0)$, which requires the voter learns that the state of the world is rightwing $\left(x_{1}=1\right.$ is then not informative since both types implement this policy in state $r$ ). Hence, a moderate right-wing incumbent is willing to choose the right-wing policy only if the electoral cost of implementing 1 rather than 0 is not too large: $(F(0)-F(-(1-\kappa) 2 \pi)) \Delta^{R}<1$. In addition, even if this condition is satisfied, it must be that the voter is sufficiently likely to learn that the state of the world is $\omega_{1}=r$. That is, media quality must be sufficiently high.

\section{Proposition 2. In a balanced media environment,}

1. If $(F(\kappa 2 \pi)-F(-(1-\kappa) 2 \pi)) \Delta^{R}<1$, in the unique PBE, a moderate politician $R$ 's first-period policy choice is his preferred policy $x^{R}\left(\omega_{1}\right)$ in all states $\omega_{1} \in\{l, c, r\}$;

2. If $(F(\kappa 2 \pi)-F(-(1-\kappa) 2 \pi)) \Delta^{R} \geq 1$, there exists a PBE in which a moderate politician $R$ 's first-period policy choice is fully revealing;

3. If $(F(0)-F(-(1-\kappa) 2 \pi)) \Delta^{R}<1 \leq(F(\kappa 2 \pi)-F(-(1-\kappa) 2 \pi)) \Delta^{R}$, there exists a threshold $\bar{\rho}_{B} \in(0,1)$ such that if and only if $\rho \geq \bar{\rho}_{B}$, there exists a PBE in which a moderate $R$ 's first-period policy choice is the voter's preferred policy $x^{V}\left(\omega_{1}\right)$ in all $\omega_{1} \in\{l, c, r\}$.

The voter is less informed in a balanced than in an unbiased media environment due to severe presentation biases. But less information can also induce a moderate incumbent to change his behavior (as long as electoral incentives are sufficiently strong). A moderate incumbent $R$ may implement the policy 0 in the centrist state (point 2.) or even the voter's preferred policy in all states of the world (point 3.). ${ }^{3}$

\section{Biased media environments}

Editorials again suffer from severe presentation bias. The right-wing outlet always states that the incumbent is moderate, and the left-wing outlet that the incumbent is extreme. Further, whenever

\footnotetext{
${ }^{3}$ The conditions for a full control PBE to exist are not knife-edge. For example, the inequalities are satisfied strictly for $\kappa=1 / 2, \pi=1 / 4$, and $\xi$ uniformly distributed over $[-\pi, \pi]$.
} 
it can affect the voter's evaluation of the incumbent, news reports suffer from some omission bias in a biased media environment as $N^{R}$ hides bad news for the incumbent and $N^{L}$ good news.

Lemma 3. Suppose the media environment is biased with $N^{J}$ only reporting, $J \in\{R, L\}$. Assume the first-period equilibrium policy choice does not reveal politician $R$ 's type. Then,

(i) $N^{J}$ 's report suffers from severe presentation bias;

(ii) There exists $\omega_{1}^{\prime} \in\{c, r\}$ such that $N^{J}$ 's news story suffers from omission bias in state $\omega_{1}^{\prime}$.

A left-leaning outlet never publishes a news story that improves the voter's evaluation of the incumbent. For example, $L$ may never reveal that $R$ 's right-wing policy choice $x_{1}=1$ matches the state of the world $\omega_{1}=r$. Upon observing $x_{1}=1$ and no news, the voter then takes into account that this may be due to the outlet's omission strategy and her posterior is higher than absent omission bias. Further, higher media quality $\rho$ implies that no news is more likely to be due to omission improving the voter's evaluation of $R$. The reasoning is reverse for the right-leaning outlet. $N^{R}$ may never disclose that $R$ 's right-wing policy $x_{1}=1$ does not match the state $\omega_{1}=r$. The voter holds a lower opinion of the incumbent after no news in a right-wing biased environment than in a balanced environment, and her posterior decreases as media quality improves.

Despite the presence of omission bias, similar PBE exist in balanced and biased media environments. Low electoral incentives are associated with no control. Strong electoral incentives can encourage the incumbent to play a fully revealing strategy to maximize his chances of reelection. In the case of intermediate electoral incentives, the full control PBE also exists for sufficiently high media quality. Importantly, this media quality threshold depends on the partisanship of the news provider due to $N^{L}$ and $N^{R}$ 's distinct omission strategies. ${ }^{4}$

Proposition 3. In a biased media environment with only $N^{J}$ reporting $(J \in\{L, R\})$, 1. If $(F(\kappa 2 \pi)-F(-(1-\kappa) 2 \pi)) \Delta^{R}<1$, in the unique PBE, a moderate politician $R$ 's first-period policy choice is his preferred policy $x^{R}\left(\omega_{1}\right)$ in all states $\omega_{1} \in\{l, c, r\}$;

2. If $(F(0)-F(-(1-\kappa) 2 \pi)) \Delta^{R} \geq 1$, there exists a PBE in which a moderate politician $R$ 's first-period policy choice is fully revealing;

3. If $(F(0)-F(-(1-\kappa) 2 \pi)) \Delta^{R}<1 \leq(F(\kappa 2 \pi)-F(-(1-\kappa) 2 \pi)) \Delta^{R}$, there exists a threshold $\bar{\rho}_{J} \in(0,1)$ such that if $\rho \geq \bar{\rho}_{J}$, there exists a PBE in which a moderate $R$ 's first-period policy choice is the voter's preferred policy $x^{V}\left(\omega_{1}\right)$ in all $\omega_{1} \in\{l, c, r\}$.

\footnotetext{
${ }^{4}$ I only state a sufficient condition for existence of a full control PBE since the voter's posterior after no news now depends on $\rho$, it is not guaranteed that there exists a unique media quality threshold above which a full control PBE exists.
} 


\section{Normative implications}

The previous section establishes that the voter is best informed in an unbiased media environment (no omission or presentation bias) and least informed in a biased media environment (presentation and some omission biases), with a balanced media environment in between (only presentation bias). Absent any change in the incumbent's behavior, an unbiased media environment always provides the highest policy welfare to the voter. With an unbiased outlet reporting, the risk of an electoral mistake is minimized since the voter learns $R$ 's type. However, when electoral incentives are relatively strong (i.e., $\left.(F(\kappa 2 \pi)-F(-(1-\kappa) 2 \pi)) \Delta^{R} \geq 1\right)$, with biased news providers, there exist PBE in which a moderate $R$ chooses policies more aligned with voter's preferences. An exclusive focus on voter information thus risks exaggerating the negative effect of biased media outlets.

As the next proposition establishes, the induced change in a moderate incumbent's actions has major welfare consequence. In equilibrium (i.e., in the PBE which maximizes the voter policy welfare), both balanced and biased media environments dominate an unbiased environment. The gain in terms of control associated with better incumbent's behavior in the first period dominates the loss in terms of selection caused by reduced information. This is due to the limited benefit from selecting a moderate politician as a type $m$ does not share the voter's policy preference in the centrist state. In contrast, control guarantees that, in the first period, the voter obtains his preferred policy at least in the most likely state $\omega_{1}=c$.

Proposition 4. The voter policy welfare is maximized in an unbiased media environment if and only if $(F(\kappa 2 \pi)-F(-(1-\kappa) 2 \pi)) \Delta^{R}<1$ and is minimized otherwise.

Proof. All proofs for the 'Normative Implications' are collected in Supplemental Appendix C (pages 30-35).

Under the assumption that the valence shock $\xi$ is uniformly distributed (over $[-(1-\kappa) 2 \pi, \kappa 2 \pi]$ for simplicity), the welfare gain from moving from an unbiased environment to a biased or balanced one becomes greater (i) when the probability a politician is moderate $(\kappa)$ increases, as selection becomes less of an issue, and (ii) when the probability the state is extreme $(\pi)$ decreases, as control becomes more valuable. ${ }^{5}$

\footnotetext{
${ }^{5}$ The assumption on $\xi$ guarantees that the direct effect of changing parameter values always dominate the indirect impact due to the shape of the valence shock.
} 
Corollary 1. Suppose $(F(\kappa 2 \pi)-F(-(1-\kappa) 2 \pi)) \Delta^{R} \geq 1$ and $\xi$ is uniformly distributed on the interval $[-(1-\kappa) 2 \pi, \kappa 2 \pi]$. The difference in voter policy welfare between a balanced or biased media environment and an unbalanced media environment is strictly increasing with $\kappa$ and strictly decreasing with $\pi$.

Proposition 4 indicates that biased media do not necessarily harm democracy. It is premature, however, to conclude that biased outlets do not affect voter welfare. We first need to compare the voter policy welfare in biased and balance media environments. To do so, the next lemma ranks fully revealing and full control PBE. Since control dominates selection, quite logically a full control PBE yields a higher policy welfare than a fully revealing PBE.

Lemma 4. The voter policy welfare is strictly higher in a full control PBE than in a fully revealing PBE in a balanced or biased media environment.

The next proposition now establishes that the voter policy welfare is always higher in a balanced media environment than in a biased media environment whenever the valence shock does not change too fast (e.g., only partisan waves can generate a big swing in $R$ 's reelection chances everything else equal). Hence, when one viewpoint dominates the media or voters self-select into echo chambers (Gentzkow and Shapiro, 2015; cf. Flaxman et al., 2016), democratic performance worsens relative to the appropriate baseline of a balanced media environment.

Proposition 5. There exists $\bar{F}>0$ such that if $\left|F^{\prime \prime}(\xi)\right| \leq \bar{F}$, in equilibrium, the voter policy welfare is weakly higher in a balanced media environment than any biased environment, strictly if and only if

(i) $(F(\kappa 2 \pi)-F(-(1-\kappa) 2 \pi)) \Delta^{R}<1$ or

(ii) $(F(0)-F(-(1-\kappa) 2 \pi)) \Delta^{R}<1 \leq(F(\kappa 2 \pi)-F(-(1-\kappa) 2 \pi)) \Delta^{R}$ and $\rho \geq \bar{\rho}_{B}$.

When a moderate incumbent plays a fully revealing strategy in the first period (i.e., $x_{1}=-1$ in state $l$ and $x_{1}=0$ otherwise), the media reporting strategy plays no role since the voter learns the incumbent's type through his policy choice. In this case, a biased and balanced media environment produces identical politicians' actions, identical electoral decision, and, thus, identical policy welfare.

Suppose now that the equilibrium exhibits full control $\left(x_{1}=x^{V}\left(\omega_{1}\right)\right)$ or no control $\left(x_{1}=\right.$ $\left.x^{R}\left(\omega_{1}\right)\right)$ in all media environments. The voter is now uncertain about the incumbent's type after observing policy $x_{1}=1$. A biased media environment then worsens selection. The left-wing 
outlet always hides good news for the incumbent (e.g., the state is $r$ after $x_{1}=1$ ) diminishing the reelection chances of moderate politicians. In turn, the right-wing outlet always hides bad news for the incumbent (e.g., the state is not $r$ ), impeding the screening of extreme politicians.

A biased media environment also affects the voter policy welfare in a subtler way by reducing a moderate incumbent's incentive to implement the voter's preferred policy in all states. A left-wing outlet reduces the electoral benefit from choosing the right-wing policy in the right-wing state $r$ since the voter never learns the incumbent is correct. A right-wing outlet increases the incentive of implementing the right-wing policy when the state is not $r$ as the mistake is not disclosed. Overall, a biased media environment makes it more difficult to sustain the welfare maximizing full control PBE.

Figure 1 illustrates Proposition 5 for the case of moderate electoral incentives (i.e., $(F(0)-F(-$ $\left.(1-\kappa) 2 \pi)) \Delta^{R}<1 \leq(F(\kappa 2 \pi)-F(-(1-\kappa) 2 \pi)) \Delta^{R}\right)$. When the media quality is relatively low $\left(\rho<\bar{\rho}_{B}\right)$, the equilibrium is always fully revealing, and the media environment has no impact on the voter policy welfare. For intermediate media quality $\left(\rho \in\left[\bar{\rho}_{B}, \bar{\rho}_{R}\right)\right)$, the full control PBE exists only in a balanced media environment, yielding a large difference in policy welfare between biased and balanced media environments. For high media quality $\left(\rho \geq \bar{\rho}_{L}\right)$, the full control equilibrium exists in all media environments, but selection is better and welfare higher in a balanced media environment.

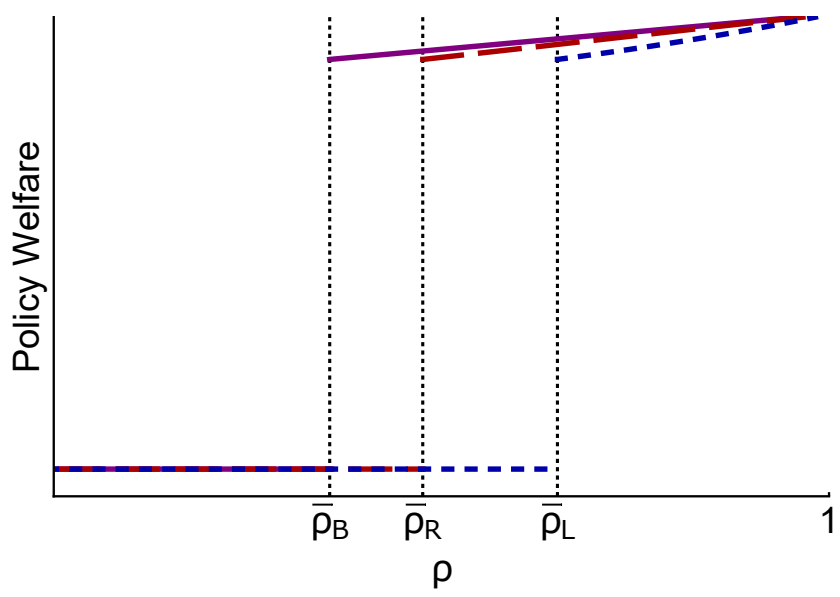

Figure 1: The effect of a balanced media environment on voter policy welfare

The purple plain line is the equilibrium voter policy welfare in a balanced media environment. The red dashed (blue short dashed) line is the equilibrium voter policy welfare in a right-wing (left-wing) biased media environment. Parameter values: $\pi=1 / 4, \kappa=1 / 2$, and $\xi$ is distributed according to a triangular distribution over the interval $[-1 / 3,1 / 3]$ with mode 0.2 . 
The welfare results described in this section are robust to several modification of the framework. First, they remain substantially unchanged under different information structure (see Supplemental Appendix E, pages 39-41). They are also likely to hold after incorporating entertainment news or the cost of producing a news story. Partisan news providers have incentives to offer better entertainment or to expend more effort uncovering news stories (e.g., Warren, 2012) since they have more to gain from convincing the voter to elect their favourite candidate.

I also conjecture the findings would survive in a game lasting more than two periods (assuming stationary equilibrium). An unbiased media outlet would still reveal the incumbent's type in his first term in office generating a loss of control in all periods. A biased media outlet's editorial would still suffer from severe presentation bias leaving the possibility for better control in a politician's first term and possibly beyond,resulting in higher policy welfare.

Behavioral extremists simplifies the analysis, but is not key for my normative conclusions. With a strategic extremist, the voter could gain control over both types rather than just moderates with biased outlets reporting. This would come at a cost in term of selection (especially when extremists have higher gain from staying in office), but the overall effect would often be positive as control dominates selection (see Appendix F, pages 42-44).

In contrast, my welfare results are likely to be reversed when the electorate harbours heterogeneous policy preferences, thus exacerbating the importance of selection. Similarly, one important class of models in which the normative conclusion would not hold are models of political posturing, in which politicians take extreme rather than moderate actions to signal their type (e.g., Fox and Stephenson, 2011; Kartik and Van Weelden, 2017). Even then, this paper stresses that scholars should examine the whole strategic interactions between the electorate, politicians, and outlets before passing judgement on the danger or benefit of certain media environments.

\section{$5 \quad$ Empirical implications}

I now turn to the empirical implications of my framework. For ease of exposition, I focus exclusively on the most interesting case: when electoral incentives are intermediary (i.e., $(F(0)-F(-(1-$ $\left.\kappa) 2 \pi)) \Delta^{R}<1 \leq(F(\kappa 2 \pi)-F(-(1-\kappa) 2 \pi)) \Delta^{R}\right)$ so the equilibrium with biased outlets reporting is either fully revealing or exhibits full control (Propositions 2 and 3). Second, I assume that the

sufficient condition described in Proposition 5 holds $\left(\left|F^{\prime \prime}(\xi)\right| \leq \bar{F}\right)$, and the CDF of the valence 
shock is either strictly concave or strictly convex over the interval $[0,2 \kappa \pi]$. (Appendix G, pages 45-47 describes the empirical implications when these assumptions are relaxed.)

From the onset, let me stress some limits to the exercise. Most prominently, a biased media environment is a theoretical construct; in practice, the electorate is always exposed to multiple sources and adjusts its media consumption as a function of the environment (Durante and Knight, 2012). The scenarios discussed below, thus, represent ideal cases (where all voters are treated), but they are still informative as long as exposure to biased news providers changes with the media environment (i.e., some voters are compliers). In addition, researchers consider vote shares as their main measure of electoral outcomes (e.g., DellaVigna and Kaplan, 2007; Gerber et al., 2009; Enikopolov et al., 2011; Gentzkow et al., 2011; DellaVigna et al., 2014; Adena et al., 2015; Barone et al., 2015; Peisakhin and Rozenas, 2017; Martin and Yurukoglu, 2017). In turn, I can only look at the ex-ante reelection probability as vote share is always zero or one with a representative voter. This is without much loss, however, as one can construct vote shares assuming a large electorate of identical voters and an i.i.d. valence shock. Finally, my set-up always includes an incumbent, whereas empirical papers also look at open races (e.g., the 2000 U.S. presidential election in DellaVigna and Kaplan, 2007). This is less of an issue if the (non-running) incumbent's past performance reveals information about his replacement's political leaning (e.g., President Bill Clinton's performance is informative of Vice-President Al Gore's ideology).

Even though the voter is sophisticated and well aware of outlets' biases and strategy, whenever the equilibrium exhibits full control, the media environment changes $R$ 's electoral fortune. Define $\mathcal{P}_{B}(\rho), \mathcal{P}_{L}(\rho)$, and $\mathcal{P}_{R}(\rho)$ the ex-ante probability that a politician $R$ is reelected as a function of media quality $\rho$ in a balanced, left-wing biased, and right-wing biased environment, respectively. I obtain:

Proposition 6. The incumbent's ex-ante reelection probabilities satisfy:

(i) $\mathcal{P}_{B}(\rho)=\mathcal{P}_{J}(\rho)$ for $J \in\{R, L\}$ if and only if $\rho<\bar{\rho}_{B}$;

(ii) $\mathcal{P}_{R}(\rho)=\mathcal{P}_{L}(\rho)$ only if $\rho<\min \left\{\bar{\rho}_{R}, \bar{\rho}_{L}\right\}$.

Proof. All proofs for the 'Positive Implications' are collected in the Supplemental Appendix D (pages 36-38).

The media environment affects $R$ 's reelection chances through two distinct channels. First, the incumbent modifies his equilibrium behavior (Propositions 2 and 3). As the next corollary shows, 
$R$ 's reelection chances are different in a fully revealing $\mathrm{PBE}$ than in a full control PBE (i.e., $R$ 's reelection probability jumps at the media quality thresholds $\left.\bar{\rho}_{J}, J \in\{B, L, R\}\right)$.

Corollary 2. The incumbent ex-ante reelection probability $\mathcal{P}_{J}(\rho), J \in\{B, L, R\}$, is almost everywhere continuous in $\rho$. It exhibits a discontinuity at $\rho=\bar{\rho}_{J}$.

$R$ 's reelection probabilities can also vary within a full control equilibrium across media environments. Recall that in a balanced media environment, there is no omission bias. One outlet's report always contains the uncovered news story. This does not hold true in a biased media environment. $N^{R}$ hides bad news for the incumbent, lowering the voter's evaluation of $R$ after no news. $N^{L}$ hides good news, increasing the voter's opinion after no news. Both lead to different reelection chances than in the scenario absent omission bias. The different reporting strategies of $N^{L}$ and $N^{R}$ also explain why the incumbent's ex-ante reelection prospects are different in left-wing and right-wing biased media environments.

Turning to the empirical literature, a majority of studies uses exogenous variation in outlets availability to measure the electoral consequence of changing the media environment (e.g., sequential entry in DellaVigna and Kaplan, 2017). This empirical strategy often holds politicians' behavior constant (e.g., because outlets are available in a small geographical area). As such, these clever designs recover the effect of changing voter information. But these empirical studies also fail to capture how politicians' behaviour may change with the media environment. Therefore, they may be of limited use to design policy responses to media mergers.

Further, empirical estimates obtained from studies exploiting exogenous variation in exposure are not easily comparable with results from works that focus on fully anticipated changes to the media environment (e.g., newspapers' entry and exit in Gentzkow et al., 2011). The latter does not just measure the effect of changing voter information, but its results also encompass office-holders' possible strategic responses. Hence, researchers should not expect these two strategies to yield similar findings (e.g., compare the results in DellaVigna and Kaplan, 2007 and Gentzkow et al., 2011).

Finally, this paper suggests that researchers should be careful when interpreting varying estimates between studies or even over time within a single study. The lack of consistency in empirical results is often attributed to changes in outlets' persuasiveness (e.g., DellaVigna and Kaplan, 2007 and Martin and Yurukoglu, 2017). My paper highlights two competing rationales. First, estimates can be affected by changes in office-holders' behaviour. As the new outlet's coverage increases, 
politicians adjust their behaviour accordingly. Second, estimates are likely to be sensitive to the political environment. Fixing the identity of reporting outlets, an office-holder's electoral chances vary with his own ideological leaning.

The model can also be used to evaluate whether empirical works measure the impact of biased media. In practice, researchers cannot directly compare electoral outcomes under unbiased and biased media environments. Rather, they use a balanced media environment as a baseline to make inferences about the consequences of media bias. This problem, well-understood when it comes to measuring the extent of media slant (Groeling, 2013), has generally been ignored when it comes to assessing the effect of biased media. The next proposition shows that it should not be. Empirical studies using a balanced media environment as the baseline are unlikely to yield proper estimate of the impact of biased media. Denote $\mathcal{P}_{U}$ the ex-ante probability that a politician $R$ is reelected when the voter's news provider is unbiased. Then, I obtain:

Proposition 7. $\mathcal{P}_{U}=\mathcal{P}_{B}(\rho)$ if and only if $\rho<\rho_{B}$

The two environments yield similar reelection probabilities only if the incumbent $R$ plays a fully revealing strategy with biased media outlets reporting. Whenever the equilibrium exhibits full control, selection becomes imperfect in a balanced media environment and the two environments are no longer observationally equivalent.

When media quality is high, current empirical research may not measure the impact of media bias, but is it still informative? The answer turns out to be negative in my set-up. Depending on parameter values, using a balanced media environment as baseline leads to upwardly biased, downwardly biased or even wrongly signed estimates of the electoral impact of media bias.

Figure 2 highlights this issue. The red plain line represents the difference in politician $R$ 's ex-ante winning probabilities in a right-wing biased compared to a balanced media environment: $\mathcal{P}_{R}(\rho)-\mathcal{P}_{B}(\rho)$. The gray dashed line is the difference in reelection probabilities in a right-wing biased media environment compared to an unbiased media environment: $\mathcal{P}_{R}(\rho)-\mathcal{P}_{U}$. For media quality lower than the threshold $\bar{\rho}_{R}$ (above which a full control PBE exists), the researcher would find a negative effect of biased media with a balanced environment as the baseline. However, media bias has no effect in practice since the incumbent plays a fully revealing strategy in both a right-wing biased and an unbiased media environment. In turn, for media quality between $\bar{\rho}_{R}$ and some $\rho^{\prime}$, empirical studies would find a smaller positive effect of biased media than it is actually the case (the red plain line is below the gray dashed line). The reverse holds true for 


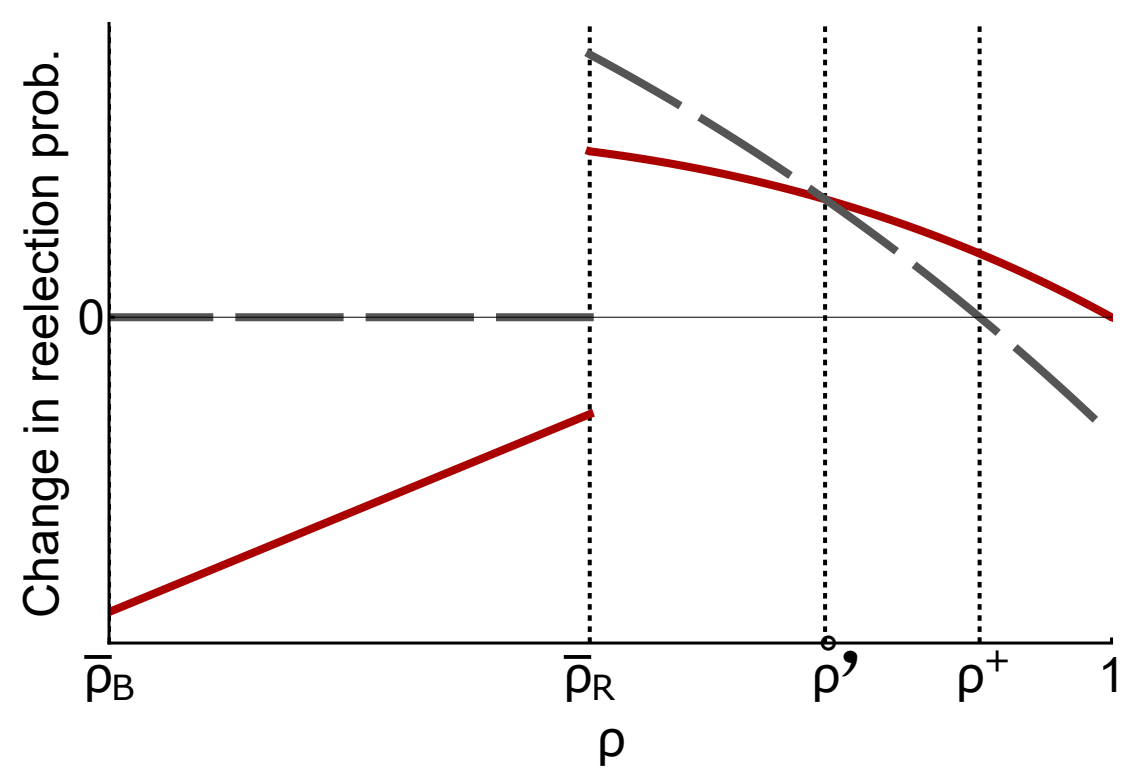

Figure 2: Media environment and reelection probability

The red plain line is $\mathcal{P}_{R}(\rho)-\mathcal{P}_{B}(\rho)$. The gray dashed line is $\mathcal{P}_{R}(\rho)-\mathcal{P}_{U}$. Parameter values: $\pi=1 / 4, \kappa=0.5$, and $F(\xi)=\widehat{F}(\xi) / \widehat{F}(\pi)$ with $\widehat{F}(\xi)=\frac{3}{2} \pi(\xi+\kappa 2 \pi)-\frac{1}{2}(\xi+\kappa 2 \pi)^{2}$ if $\xi \in\left[-\kappa 2 \pi,-\left(\frac{1}{4}-\kappa\right) 2 \pi\right]$ and $\widehat{F}(\xi)=\frac{1}{2}\left(\frac{3}{2} \pi\right)^{2}+\frac{5}{2}(\xi+$ $\left.\left(\frac{1}{4}-\kappa\right) 2 \pi\right)^{2}$ if $\xi \in\left[-\left(\frac{1}{4}-\kappa\right) 2 \pi, \kappa 2 \pi\right]$.

$\rho \in\left[\rho^{\prime}, \rho^{+}\right]$. Worse, empirical research may find that a biased outlet improves the incumbent's electoral chances compared with a balanced environment as baseline when it actually decreases the incumbent's reelection probability compared to coverage by an unbiased news provider (for $\left.\rho \geq \rho^{+}\right)$.

Let me stress that a balanced media environment is a poor approximation of an unbiased environment only if outlets can engage in presentation bias. In settings where information is likely to be verifiable, researchers may, thus, recover the impact of biased media. Further, current estimates still measure important quantities. Existing empirical findings are especially relevant when there is no possibility (or no desire) to guarantee that news providers are unbiased. Yet, even so, estimates vary as a function of the political and media environments under scrutiny. Hence, a richer description of these factors can then lead to better comparability across studies and more informed policy-making.

\section{Conclusion}

Writing in the New York Times in 2015, Timothy Carney asserts that "[n]ews media bias is real. It reduces the quality of journalism, and it fosters distrust among readers and viewers. This is bad for democracy." This paper shows that Carney is only partially correct. Media bias does 
reduce the quality of journalism and fosters distrust due to presentation bias. However, it is not necessarily bad for democracy. Due to office-holders' strategic responses, a biased or balanced media environment can yield higher voter welfare than an unbiased environment.

The strategic interplay between news providers, politicians, and voters also has important implications for empirical research. The electoral consequences of changing the media environment depends on the political situation, especially incumbents' partisan identities. Thus, researchers should use caution when interpreting varying estimates across studies or over time within a single study. Further, different news providers may induce different policy choices. Looking only at voter information or electoral outcomes may not be sufficient to understand the impact of biased media. A more comprehensive approach that also considers office-holders' actions-along the lines of Snyder and Strömberg (2010) for media penetration-seems necessary. Even then, due to presentation biases, a balanced media environment is a poor approximation for an unbiased environment making it difficult to empirically evaluate the impact of media bias.

At a deeper level, the present work joins a few papers proposing a new link between theory and empirics. Rather than focusing on comparative statics (Ashworth and Bueno de Mesquita, 2006), these studies (re)assess in various contexts what empirical estimates actually measure (e.g., Eggers, 2017 for the incumbency effect; Wolton, 2017 for special interest group influence). This approach, broadly defined, uses formal reasoning to rethink empirical counterfactuals. ${ }^{6}$ It is best described as 'Theoretical Implications of Empirical Models' (TIEM). Given that counterfactuals are at the core of any empirical work claiming causality (Fearon, 1991), the applications of TIEM logic are potentially numerous. A full analysis of the benefits and pitfalls of this approach could generate new fruitful complementarities between empirical and formal works.

\footnotetext{
${ }^{6}$ This approach is related to, but not equivalent to the analysis of historical events with game theoretical models that rely on off-path behavior (see Weingast, 1996). The counterfactual analysis I briefly describe is grounded in on-path behavior to make sense of observables.
} 


\section{References}

Adachi, Takanori, and Yoichi Hizen. 2014. "Political Accountability, Electoral Control, and Media Bias." The Japanese Economic Review 65(3): 316-343.

Adena, Maja, Ruben Enikolopov, Maria Petrova, Veronica Santarosa, and Ekaterina Zhuravskaya. 2015. "Radio and the Rise of the Nazis in Prewar Germany." The Quarterly Journal of Economics 130(4): 1885-1939.

Anderson, Simon P., and John McLaren. 2012. "Media mergers and media bias with rational consumers." Journal of the European Economic Association 10(4): 831-859.

Ashworth, Scott, and Ethan Bueno de Mesquita. 2006. "Monotone comparative statics for models of politics." American Journal of Political Science 50(1): 214-231.

Ashworth, Scott, and Ethan Bueno De Mesquita. 2014. "Is voter competence good for voters?: Information, rationality, and democratic performance." American Political Science Review 108(3): 565-587.

Ashworth, Scott, and Kenneth W. Shotts. 2010. "Does informative media commentary reduce politicians' incentives to pander?." Journal of Public Economics 94(11): 838-847.

Barone, Guglielmo, Francesco D’Acunto, and Gaia Narciso. 2015. "Telecracy: Testing for channels of persuasion." American Economic Journal: Economic Policy 7(2): 30-60.

Battaglini, Marco. 2002. "Multiple referrals and multidimensional cheap talk." Econometrica 70(4): 1379-1401.

Bernhardt, Dan, Stefan Krasa, and Mattias Polborn. 2008. "Political polarization and the electoral effects of media bias." Journal of Public Economics 92(5): 1092-1104.

Bonica, Adam, Nolan McCarty, Keith T. Poole, and Howard Rosenthal. 2013. "Why hasn't democracy slowed rising inequality?." The Journal of Economic Perspectives 27(3): 103-123.

Canes-Wrone, Brandice, Michael C. Herron, and Kenneth W. Shotts. 2001. "Leadership and pandering: A theory of executive policymaking." American Journal of Political Science 45(3): 532-550.

Carney, Timothy P. 2015. "Liberal News Media Bias Has a Serious Effect." New York Times Opinion Pages, November 11. Last accessed September 19, 2018: http://www.nytimes.com/roomfordebate/2015/11/11/why-has-trust-in-the-news-mediadeclined/liberal-news-media-bias-has-a-serious-effect.

Chakraborty, Archishman, and Parikshit Ghosh. 2016. "Character endorsements and electoral competition." American Economic Journal: Microeconomics 8(2): 277-310.

Chan, Jimmy, and Wing Suen. 2009. "Media as watchdogs: The role of news media in electoral competition." European Economic Review 53(7): 799-814.

Chen, Viola. 2007. "Is Media Bias Bad?." Unpublished manuscript: Federal Trade Commission. Available at http://chenv.bol.ucla.edu/ChenV_Bias.pdf 
DellaVigna, Stefano, and Ethan Kaplan. 2007. "The Fox News effect: Media bias and voting." The Quarterly Journal of Economics 122(3): 1187-1234.

DellaVigna, Stefano, Ruben Enikolopov, Vera Mironova, Maria Petrova, and Ekaterina Zhuravskaya. 2014. "Cross-border media and nationalism: Evidence from Serbian radio in Croatia." American Economic Journal: Applied Economics 6(3): 103-132.

Duggan, John, and Cesar Martinelli. 2011. "A spatial theory of media slant and voter choice." The Review of Economic Studies 78(2): 640-666.

Durante, Ruben, and Brian Knight. 2012. "Partisan control, media bias, and viewer responses: Evidence from Berlusconi's Italy." Journal of the European Economic Association 10(3): 451-481.

Eggers, Andrew C. 2017. "Quality-Based Explanations of Incumbency Effects." The Journal of Politics 79(4): 1315-1328.

Enikolopov, Ruben, Maria Petrova, and Ekaterina Zhuravskaya. 2011. "Media and political persuasion: Evidence from Russia." American Economic Review 101(7): 3253-85.

Entman, Robert M. 1989. Democracy without citizens: media and the decay of American politics. New York: Oxford University Press.

Fearon, James D. 1991. "Counterfactuals and hypothesis testing in political science." World politics 43(2): 169-195.

Fearon, James D. 1999. "Electoral Accountability and the Control of Politicians: Selecting Good Types versus Sanctioning Poor Performances" in Democracy, accountability, and representation, Adam Przeworski, Susan C. Stokes, and Bernard Manin eds. New York: Cambridge University Press.

Flaxman, Seth, Sharad Goel, and Justin M. Rao. 2016. "Filter bubbles, echo chambers, and online news consumption." Public opinion quarterly 80(1): 298-320.

Fox, Justin. 2007. "Government transparency and policymaking." Public choice 131(1-2): 23-44.

Fox, Justin, and Matthew C. Stephenson. 2011. "Judicial review as a response to political posturing." American Political Science Review 105(2): 397-414.

Fox, Justin, and Richard Van Weelden. 2012. "Costly transparency." Journal of Public Economics 96(1): 142-150.

Gentzkow, Matthew, Jesse M. Shapiro, and Michael Sinkinson. 2011. "The effect of newspaper entry and exit on electoral politics." The American Economic Review 101(7): 2980-3018.

Gentzkow, Matthew, Jesse M. Shapiro, and Daniel F. Stone. 2015a. "Media bias in the marketplace: Theory" in in Handbook of Media Economics, vol 1A, first edition, Simon Anderson, David Strömberg, and Joel Waldfogel edts. Amsterdam, The Netherlands: North-Holland.

Gentzkow, Matthew, Jesse M. Shapiro, and Daniel F. Stone. 2015b. "Ideology and Online News." in Economic Analysis of the Digital Economy. Avi Goldfarb, Shane M. Greenstein, and Catherine E. Tucker, edts. Chicago, Il: Chicago University Press. 
Gerber, Alan S., Dean Karlan, and Daniel Bergan. 2009. "Does the media matter? A field experiment measuring the effect of newspapers on voting behavior and political opinions." American Economic Journal: Applied Economics 1(2): 35-52.

Gratton, Gabriele. 2015. "The sound of silence: Political accountability and libel law." European Journal of Political Economy 37: 266-279.

Groeling, Tim. 2013. "Media bias by the numbers: Challenges and opportunities in the empirical study of partisan news." Annual Review of Political Science 16: 129-151.

Hafer, Catherine, Dimitri Landa, and Patrick Le Bihan. 2016. "Who Gets the Credit? NewsGathering Competition and Political Accountability." New York University working paper. https://pdfs.semanticscholar.org/news.pdf

Kartik, Navin and Richard Van Weelden. $2017 . \quad$ "Informative cheap talk in elections." Review of Economic Studies, forthcoming. https://sites.googlegroups.com/site/richvanweelden/files/cheaptalk.pdf

Ladd, Jonathan M. 2012. Why Americans Hate the Media and How it Matters. Princeton: Princeton University Press.

Martin, Gregory J., and Ali Yurukoglu. 2017. "Bias in Cable News: Persuasion and Polarization." American Economic Review 107(9): 2565-99.

Maskin, Eric, and Jean Tirole. 2004. "The politician and the judge: Accountability in government." The American Economic Review 94(4): 1034-1054.

McChesney, Robert W. 2004. The problem of the media: U.S. communication politics in the twenty-first century. New York: Monthly Review Press.

Milgrom, Paul, and John Roberts. 1986. "Relying on the information of interested parties." The RAND Journal of Economics 17(1): 18-32.

Miura, Shintaro. 2018. "Manipulated News Model: Electoral Competition and Mass Media." Games and Economic Behavior, forthcoming. https://www.sciencedirect.com/science/article/pii/S0899825618301507.

Morelli, Massimo, and Richard Van Weelden. 2013. "Ideology and information in policymaking." Journal of Theoretical Politics 25(2): 412-439.

Mullainathan, Sendhil, and Andrei Shleifer. 2005. "The market for news." American Economic Review 95(4): 1031-1053.

Newseum Institute. 2017. The State of the First Assessment. Last accessed: July, 312017. http://www.newseuminstitute.org/FAC_SOFA17_report.pdf.

Peisakhin, Leonid and Arturas Rozenas. 2018. "Electoral Effects of Biased Media: Russian Television in Ukraine." American Journal of Political Science 62(3): 535-550.

Piolatto, Amedeo and Florian Schuett. 2015. "Media competition and electoral politics." Journal of Public Economics 130: 80-93. 
Prat, Andrea. 2005. "The Wrong Kind of Transparency." The American Economic Review 95(3): 862-877.

Prior, Markus. 2013. "Media and political polarization." Annual Review of Political Science 16: 101-127.

Puglisi, Riccardo, and James M. Snyder. 2015a. "Media Bias in the Marketplace: Empirics" in Handbook of Media Economics, vol 1A, first edition, Simon Anderson, David Strömberg, and Joel Waldfogel edts. Amsterdam, The Netherlands: North-Holland.

Puglisi, Riccardo, and James M. Snyder. 2015b. "The balanced US press." Journal of the European Economic Association 13(2): 240-264.

Reuters Institute. 2015. Digital News Report 2015: Trust in the News. Last accessed: March, 29 2016. http://www.digitalnewsreport.org/survey/2015/trust-in-the-news-2015/

Shapiro, Jesse M. 2016. "Special interests and the media: Theory and an application to climate change." Journal of Public Economics 144: 91-108.

Sobbrio, Francesco. 2011. "Indirect Lobbying and Media Bias." Quarterly Journal of Political Science, 6(3-4): 235-274.

Snyder Jr, James M. and David Strömberg. 2010. "Press coverage and political accountability." Journal of political Economy 118, no. 2 (2010): 355-408.

Strömberg, David. 2015. "Media and Politics." Annual Review of Economics 7(1): 173-205.

Warren, Patrick L. 2012. "Independent auditors, bias, and political agency." Journal of Public Economics 96(1): 78-88.

Weingast, Barry R. 1996. "Off-the-path behavior: a game-theoretic approach to counterfactuals and its implications for political and historical analysis" in Counterfactual thought experiments in world politics: Logical, methodological, and psychological perspectives, Philip E. Tetlock and Aaron Belkin, eds. Princeton, NJ: Princeton University Press.

Wolton, Stephane. 2017. "Lobbying Inside Out: How Special Interest Groups Influence Policy Choices." LSE Working Paper. Available at https://papers.ssrn.com/sol3/papers.cfm?abstract_id=2190685. 